\title{
Prolapso retal em pequenos ruminantes: etiologia, técnicas anestésicas e cirúrgicas e evolução clínica em 12 animais - relato de caso
}

B.R.F. Schuh1, https://orcid.org/0000-0002-9152-3944 K.R.J.L. Lera1, https://orcid.org/0000-0002-6365-6029 L.A.O. Paula https://orcid.org/0000-0002-2998-3405 L. Prado1

https://orcid.org/0000-0002-4802-5480

https://orcid.org/0000-0003-1262-2125

[Rectal prolapse in small ruminants: etiology, anesthetic and surgical techniques, and outcome in 12 animals - case report]

B.R.F. Schuh ${ }^{1}$, K.R.J.L. Lera ${ }^{1}$, , L.A.O. Paula ${ }^{1}$, I.L. Prado ${ }^{1}$, G.M. Pagliosa ${ }^{1 *}$

Universidade Federal do Paraná - Palotina, PR

\section{RESUMO}

Este relato descreve o prolapso retal de grau II intermitente ou permanente em nove ovinos e três caprinos. Para se estabelecer e tratar a causa primária, o histórico clínico foi minuciosamente explorado, sendo complementado pelo atendimento a campo. Nos pacientes predominou sobrepeso e tosse devido à pneumonia e, em menor proporção, verminose e prenhez. Entre os fatores predisponentes identificados na propriedade estavam a inadequada ventilação e o excesso de poeira e amônia nas instalações, o que foi associado à prevalência alta de pneumonia. O tratamento incluiu a redução manual (T1) ou a amputação retal (T2), mediante anestesia epidural sacrococcígea ou lombossacral, respectivamente, com ou sem neuroleptoanalgesia, seguidas de sutura perianal em bolsa de tabaco captonada. Os tratamentos foram eficazes em todos os animais, embora com recidiva e necessidade de nova intervenção em dois pacientes após seu retorno à propriedade. Segundo a literatura consultada, este é o primeiro relato de prolapso em caprinos. Conclui-se que o histórico e a avaliação da propriedade são importantes para identificar e tratar a causa primária do prolapso, evitando-se recidivas, e que a cirurgia e o protocolo anestésico aqui utilizados foram eficientes e podem ser praticados mesmo em condições de campo.

Palavras-chave: ovino, caprino, reto, obesidade, pneumonia

\begin{abstract}
Nine ovine and three caprine with grade II intermittent or permanent rectal prolapse were treated, with the first report in caprine, according to the consulted literature. The clinical history was deeply explored with the clinical evaluation of the livestock. Among the causative factors identified were the inappropriate ventilation with high levels of dust and ammonia in the facilities, which was correlated to the high incidence of pneumonia and cough. The causative factors identified in the patients were overweight, pneumonia and cough, and, less predominately, verminosis and pregnancy. The treatment was based on manual reduction (T1) or rectal amputation (T2), under sacrococcygeal or lombossacral epidural anesthesia, with or without neuroleptic analgesia. The treatments were efficient in all patients; although there was recurrence in two animals, which needed the repetition of the treatment after their delivery to the farm. Based on the cases reported here, it can be concluded that the history and the livestock clinical evaluation are important to identify the primary causes, avoiding relapses. It also concluded that the surgical treatment and the anesthetic protocol used in the patients reported here were efficient and can be applied even under field conditions.
\end{abstract}

Keywords: ovine, caprine, rectum, obesity, pneumonia

Recebido em 27 de fevereiro de 2019

Aceito em 9 de abril de 2019

*Autor para correspondência (corresponding author)

E-mail: geanepagliosa@gmail.com 


\section{INTRODUÇÃO}

O prolapso retal é uma enfermidade multifatorial de prevalência alta em pequenos ruminantes, caracterizada pela protrusão de uma ou mais camadas do reto através do ânus (Anderson e Miesner, 2008). Entre os fatores etiológicos mais frequentemente descritos estão comprimento da cauda, dieta, sexo e genética, associados ou não a condições que provocam aumento de pressão intra-abdominal, como tenesmo, disúria e tosse crônica (Thomas et al., 2003; Huaixan et al., 2011; Zanolini et al., 2014).

Conforme a estrutura anatômica exposta e a gravidade, o prolapso pode ser classificado nos graus I, II, III e IV, com exposição da mucosa, da mucosa e serosa, do cólon maior e do cólon maior com constrição de reto, e do cólon, respectivamente (Steiner, 2004). Os graus I e II são de maior prevalência e, apesar de serem menos graves, podem ser fatais, pois, assim como os demais, podem predispor à prolapso intestinal e sepse (Anderson e Meisner, 2008). O tratamento do prolapso retal inclui identificação dos fatores predisponentes, diminuição da irritação da mucosa, eliminação da causa de esforço abdominal e resolução cirúrgica menos ou mais invasiva, dependendo da condição do tecido prolapsado e do grau do prolapso (Steiner, 2004).

Embora de prevalência alta em pequenos ruminantes, existem poucos relatos na literatura consultada em ovinos e nenhum em caprinos (Huaixan et al., 2011; Oliveira et al., 2009). Este trabalho tem o objetivo de relatar 12 casos de prolapso retal em ovinos e caprinos, destacando os fatores etiológicos, as técnicas cirúrgicas, as condutas anestésicas utilizadas, factíveis mesmo em condições de campo, bem como a conduta pós-operatória e a evolução dos pacientes.

\section{CASUÍSTICA}

Três cabras da raça Boer e nove ovinos, cinco machos e três fêmeas da raça Dorper e uma fêmea da Raça Santa Inês, com prolapso retal de grau II intermitente ou permanente, com idade entre cinco e 36 meses, foram atendidos pelo Setor de Grandes Animais UFPR - Setor Palotina. Onze desses animais foram atendidos a campo, sendo seis posteriormente encaminhados à universidade. Foi obtido histórico completo e, nos pacientes atendidos a campo, também foi realizada a avaliação do manejo sanitário e nutricional relacionados ao paciente e ao rebanho. No exame físico, os parâmetros vitais, excetuando-se a termometria, foram conduzidos de acordo com Feitosa (2008), sendo o prolapso classificado segundo Steiner (2004) (Fig. 1a). Em todos os pacientes, foram realizados a coproscopia parasitária e o hemograma completo.

O tipo de tratamento consistiu na redução manual e no posicionamento do reto em seu local anatômico, seguido de sutura perianal em bolsa de tabaco captonada (T1 - tratamento 1) ou amputação retal (T2 - tratamento 2). Para o T1, foi realizada anestesia epidural sacrococcígea com lidocaína a $2 \%$, no volume de $1 \mathrm{~mL}$ (Fig. 1b), seguida de limpeza e antissepsia da região prolapsada e compressa com água fria e açúcar (Fig. 1c). A sutura em bolsa de tabaco foi realizada com fio de poliamida (náilon) $\mathrm{n}^{\circ} 0 \mathrm{e}$ captons produzidos com sonda uretral $\mathrm{n}^{\circ} 10$ (Fig. 1d). Essa sutura era passada no subcutâneo da região perianal, de 2 a $4 \mathrm{~cm}$ de distância da abertura anal, como orientado por Anderson e Miesner (2008). Essa técnica foi utilizada em sete pacientes atendidos na propriedade e a sutura perianal foi mantida por cinco a sete dias, com exceção de uma das cabras, a qual foi mantida por 21 dias, devido à gestação avançada, sendo retirada no dia posterior ao parto.

O T2 foi realizado em seis pacientes. Para esse procedimento, os animais foram submetidos a 24 horas de jejum alimentar, sem restrição hídrica. Antes da cirurgia, foi realizado enema com soro fisiológico acrescido de $1 \%$ de clorexidina degermante para remover as fezes e higienizar a ampola retal. $\mathrm{O}$ protocolo anestésico foi iniciado com medicação pré-anestésica (MPA) à base de xilazina $(0,1 \mathrm{mg} / \mathrm{kg})$ associada à meperidina $(0,3 \mathrm{mg} / \mathrm{kg})$, por via intramuscular (IM), seguida de anestesia epidural lombossacra com lidocaína a $2 \%$, na dose de $0,14 \mathrm{~mL} / \mathrm{kg}$ (Edmondson, 2016). A técnica cirúrgica empregada foi descrita por Anderson e Miesner (2008) (Fig. 2a), utilizando-se fio de ácido poliglicólico $\mathrm{n}^{\circ} 0 \mathrm{em}$ padrão de sutura Sultan (Fig. 2b). Como último procedimento, a sutura perianal em bolsa de tabaco captonada foi aplicada da mesma forma descrita no T1. 


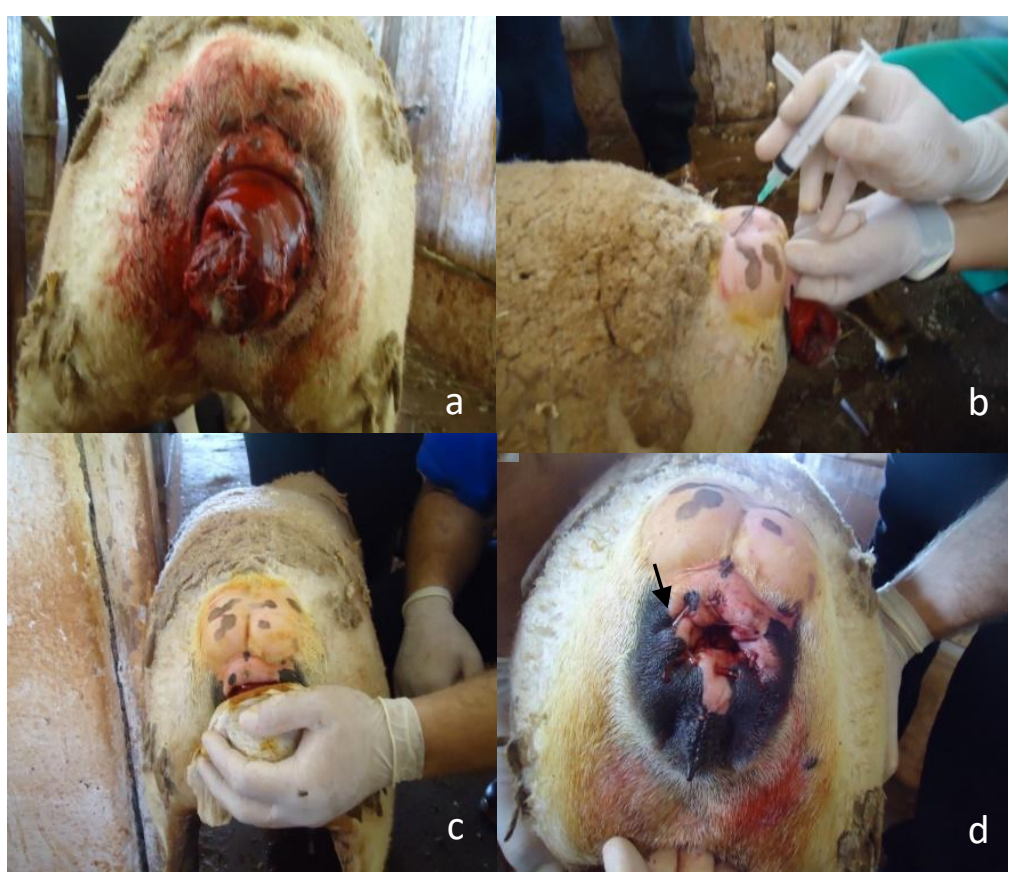

Figura 1. Ovino portador de prolapso retal permanente de grau II (a), submetido à redução manual do prolapso sem amputação de reto (tratamento T1), iniciada por anestesia epidural sacrococcígea (b), seguida de compressa com água gelada e açúcar (c) e finalizada com sutura perianal em bolsa de tabaco (d) captonada (seta).

O pós-operatório de todos os animais consistiu de terapia sistêmica com flunixina meglumina $(1,1 \mathrm{mg} / \mathrm{kg}$, IM) por três dias e ceftiofur $(2,2 \mathrm{mg} / \mathrm{kg}, \mathrm{IM})$ por cinco a 10 dias, dependendo se o paciente era portador de pneumonia. $\mathrm{Na}$ região perianal, foi realizada antissepsia com iodovinilpirrolidona degermante e tópica até a retirada da sutura e, nos animais hospitalizados, também a compressa de água fria até o terceiro dia de pós-operatório. A dieta consistiu em forragem verde por 15 dias, após o qual houve retorno gradual da oferta de feno e de concentrado.

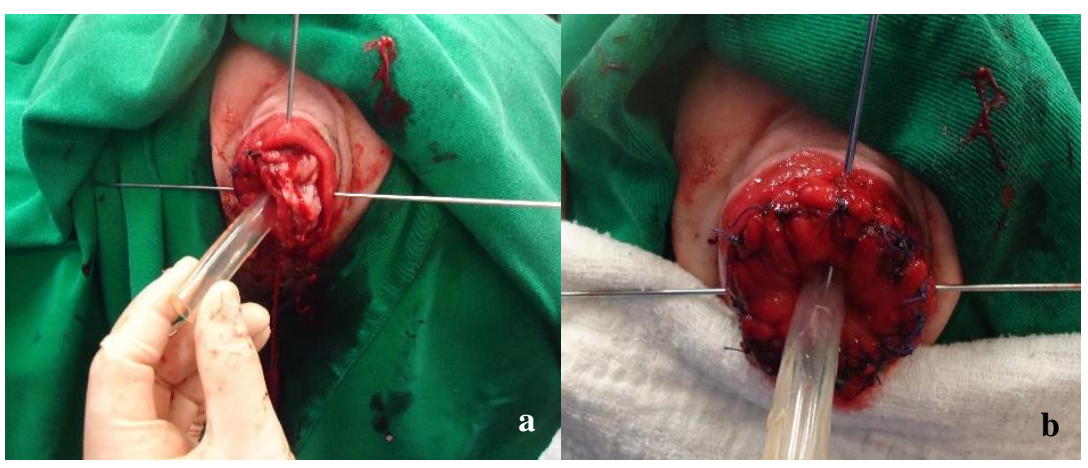

Figura 2. Ovino portador de prolapso retal permanente de grau II submetido à amputação de reto (tratamento T2). Um tubo de silicone é introduzido no reto e fixado por dois pinos de Steinmann cruzando-se entre si em ângulo de 90 para evitar que, após a amputação da parte prolapsada, seja possível realizar-se a sutura entre as mucosas interna e externa do reto (a). Sutura em padrão de Sultan com fio de ácido poliglicólico unindo as mucosas interna e externa do reto em todo o seu diâmetro, ao final da cirurgia e antes da remoção dos pinos e o tubo de silicone (b). 


\section{DISCUSSÃO}

O prolapso retal é uma condição multifatorial na qual, independentemente do fator ou fatores primários, o resultado final é a exposição da mucosa retal interna devido ao excesso de pressão ou exigência biomecânica sobre o tônus da musculatura lisa ou estriada do esfíncter anal (Anderson e Miesner, 2008). Em razão da natureza multifatorial, é imperativa a investigação minuciosa das possíveis causas em pacientes portadores dessa afecção, o que fez o histórico ser bastante explorado nos animais descritos neste relato. A avaliação de rebanho foi realizada em 11 dos 12 pacientes e foi tão ou mais importante que as informações fornecidas pelo produtor por complementá-las e permitir avaliar a situação de risco de outros animais desenvolverem o problema ou de o paciente atendido ter recidiva. Em nove dos 12 animais foram identificadas, como possíveis causas de desenvolvimento do prolapso, obesidade e pneumonia, tendo as visitas às propriedades auxiliado a entender o desenvolvimento dessas características e seu controle.

A prevalência alta de pneumonia nos animais atendidos neste relato foi principalmente associada às condições de ambiência inadequadas na propriedade, onde se destacava a insuficiente ventilação das instalações e higienização das camas, com consequente excesso de poeira e odor de amônia, respectivamente. O ruminante possui um sistema de depuração do ar de vias aéreas superiores pouco eficiente à presença ambiental constante de excesso de poeira e amônia, além de uma frequência respiratória em repouso mais elevada que outras espécies, o que o torna mais susceptível a doenças respiratórias (Mortola e Lanthier, 2007). Todos os animais deste relato possuíam alteração à auscultação pulmonar e em quatro deles o produtor relatou ter percebido tosse ou esta foi observada durante o exame clínico. A tosse cria um aumento de pressão abdominal durante sua ocorrência, que consiste em um dos mecanismos etiopatogênicos de prolapso retal (Anderson e Meisner, 2008).

O sobrepeso estava presente em nove dos 12 pacientes e é um dos fatores etiológicos citados na literatura (Anderson e Miesner, 2008; Oliveira et al., 2009), particularmente em fêmeas da raça Dorper. Nos animais deste relato, o sobrepeso ocorreu em igual número em machos e fêmeas da raça Dorper. A avaliação do acúmulo de gordura em ovinos dessa raça que receberam dietas ricas em energia durante a fase de crescimento, como os animais aqui relatados, não diferiu para machos e fêmeas, segundo resultados de Marais et al. (1991). Assim, acredita-se que machos e fêmeas da raça Dorper possuem a mesma predisposição de prolapso retal devido à obesidade. Não se considera possível fazer a mesma comparação entre os caprinos com sobrepeso atendidos neste relato, pois somente fêmeas foram atendidas e, adicionalmente, duas delas estavam com prenhez adiantada.

A prenhez adiantada pode predispor ao prolapso retal devido ao aumento de pressão intraabdominal pelo útero gravídico e aos níveis plasmáticos elevados de estrógeno que ocorrem a partir do último mês de gestação, de forma mais significativa (Anderson e Miesner, 2008; Alwan et al., 2010). Neste relato foram atendidas uma cabra e uma ovelha com gestação em 130 e 120 dias, respectivamente, nas quais não foi identificado nenhum outro fator etiológico além da gestação. Por outro lado, em uma cabra atendida com 75 dias de gestação, não se considera que essa condição foi o fator mais importante, pois, além de o período gestacional não corresponder ao último mês, a paciente era portadora de sobrepeso e alta carga parasitária de Eimeria sp., causas essas também atribuídas na etiologia do prolpaso (Anderson e Miesner, 2008).

Diarreia e enterites parasitárias estão citadas entre os fatores etiológicos de prolapso retal em pequenos ruminantes (Steiner, 2004; Anderson e Miesner, 2008). A coproscopia parasitária realizada nos animais deste relato foi com base em OPG (ovos por grama de fezes) ou OOPG (oocistos por grama de fezes) após a correção do prolapso retal. Os graus de infestação obtidos foram 33\% para leve (quatro animais, OPG < 500 ), 59\% para moderada (seis animais, $500<$ OPG < 1.000) e $25 \%$ para alta (três animais, $1.501<\mathrm{OPG}<3000$ ) (Ueno e Gonçalves, 1998). Oocistos de Eimeria sp. foram encontrados em dois animais em carga moderada (1.200 OOPG) e alta (4.000 OOPG). Em 84,6\% dos pacientes deste relato, a vermifugação era realizada mensalmente, assim como em todos os animais do rebanho, sem nenhum outro critério. As fezes de todos os animais estavam pastosas e com 
quantidades variáveis de muco e apenas no paciente com alta infestação por Eimeria sp. continham sangue vivo. $\mathrm{O}$ antiparasitário utilizado nos pacientes tratados foi do grupo dos benzimidazóis ou imidotiazóis, evitando-se o uso do mesmo princípio ativo utilizado na propriedade; ou o toltrazuril nos pacientes portadores de Eimeria sp. Nos pacientes deste relato, a parasitose só foi considerada causa única de prolapso na paciente com alta carga de Eimeria sp. Nos demais pacientes, considerou-se a verminose como um adicional influente mas não determinante, por haver outros sinais, como obesidade e tosse associados, que se julgou serem mais importantes como fator etiológico.

A caudectomia curta é um dos fatores etiológicos de prolapso retal mais discutidos na literatura consultada, a qual orienta a manutenção de, no mínimo, duas vértebras coccígeas (Thomas et al., 2003; Zanolini et al., 2014). De fato, parte do tônus do esfíncter anal também é mantido pela movimentação da cauda, especialmente em sentido ventral (Thomas et al., 2003), e esse mecanismo pode ser prejudicado em animais com caudectomia curta. Nos animais descritos neste relato, a caudectomia curta somente foi observada em um dos ovinos e, obviamente, não se aplica aos caprinos. Embora a caudectomia curta seja um fator importante a ser avaliado, não se considera que essa condição influenciou o desenvolvimento do prolapso retal nos pacientes deste relato.

Os protocolos anestésicos escolhidos para o T1 e o T2 foram considerados eficientes e seguros, além de tecnicamente simples e factíveis de serem praticados, mesmo em condições de campo (Edmondson, 2016). A literatura descreve o uso do propofol como agente indutor e o isoflurano para a manutenção de anestesia em ovinos submetidos à mesma técnica de amputação de reto como a realizada neste relato (Huaixan et al., 2011). Embora esse protocolo também seja uma alternativa, possui mais riscos devido à hipotensão e à depressão respiratória, além de maior custo e necessidade de aparelho de anestesia (Edmondson, 2016).

$\mathrm{O}$ tratamento $\mathrm{T} 1$ foi realizado em seis animais, com início do prolapso até sua resolução cirúrgica variando de um a 15 dias. O critério para a decisão do tratamento $\mathrm{T} 1$ foi a possibilidade de redução manual, como recomendado por outros autores (Steiner, 2004; Anderson e Meisner, 2008; Huaixan et al., 2011), a qual foi auxiliada pela anestesia epidural, a compressa fria, como adotado por Huaixan et al. (2011), e o açúcar associado, que, além de auxiliar na diminuição do edema, tem propriedade bactericida. $\mathrm{O}$ tratamento $\mathrm{T} 2$ foi utilizado em seis animais deste relato, todos ovinos, sendo um deles uma ovelha Santa Inês com prenhes de 120 dias, que manteve a gestação a termo. Todos os animais tiveram recuperação satisfatória, embora um dos ovinos tenha tido recidiva após ser liberado à propriedade. Esse paciente foi submetido a uma segunda amputação sem recidivas, sendo mantido como reprodutor há mais de três anos.

A literatura consultada orienta a realização da sutura perianal em bolsa de tabaco com fio de poliéster e sua manutenção por cinco a 10 dias, período suficiente para a inflamação da mucosa retal diminuir, reduzindo-se a chance de recidivas (Anderson e Miesner, 2008). Nos animais do presente relato, o fio de escolha para realização da sutura perianal foi a poliamida (náilon) $\mathrm{n}^{\circ} 0$. Apesar de ser monofilamentar e pouco reativa, devido à sua alta memória e baixa pliabilidade, optou-se pelo uso do capton para melhorar o conforto do paciente, especialmente quando havia necessidade da permanência do fio de sutura por período prolongado. Não foi encontrado, na literatura consultada, o uso de captons em sutura perianal em bolsa de tabaco e sugere-se que seja considerada sua associação com o náilon, como nos pacientes deste relato.

\section{CONCLUSÕES}

Com base na descrição dos casos aqui relatados, pode-se concluir que o sobrepeso, a pneumonia e a gestação avançada, isolados ou associados, são causas de prolapso retal e que a amputação de reto pode ser realizada com sedação e anestesia lombossacral. Adicionalmente, a sutura em bolsa de tabaco captonada promove conforto mecânico e pode ser mantida por até 21 dias. 


\section{REFERÊNCIAS}

ALWAN, A.F.; AMIN, F.A.M.; IBRAHIN, M.S. Blood progesterone and estrogen hormones level during pregnancy and after birth in Iraq sheep and goat. Basrah J. Vet. Res., v.10, p.153-157, 2010 .

ANDERSON, D.E.; MIESNER, M.D. Rectal prolapse. Vet. Clin. N. Am. Food Anim. Pract., v.24, p.403-408, 2008.

EDMONDSON, M.A. Local, regional, and spinal anesthesia in ruminants. Vet. Clin. N. Am. Food Anim. Pract., v.32, p.535-552, 2016.

FEITOSA, F.L.F. Semiologia veterinária: a arte do diagnóstico. 2.ed. São Paulo: Roca, 2008. $792 \mathrm{p}$.

HUAIXAN, L.N.; VILLA FILHO, P.C.; XIMENES, F.H.B. et al. Estudo retrospectivo de 13 casos de ressecção de reto em ovinos da raça Dorper atendidos no hospital veterinário de grandes animais da Universidade de Brasília. Vet. Zootec., v.18, Sup.3, p.500-502, 2011.

MARAIS, P.G.; VAN DER MERWE, H.J.; DU TOIL, J.E.J. The efficiency of protein and fat deposition during growth in Dorper sheep. S. Afr. J. Anim. Sci., v.21, p.103-107, 1991.
MORTOLA, J.P.; LANTHIER, C. Breathing frequency in ruminants: comparative analysis with non-ruminants mammals. Resp. Physiol. Neurobiol., v.145, p.265-277, 2007.

OLIVEIRA, G.Z.; OLIVEIRA, C.K.; RAISER, A.G. et al. Colopexia em ovinos da raça Dorper com prolapso retal. Cienc. Rural, v.39, p.479483, 2009.

STEINER, A. Sugery of the bovine digestive system. In: FUBINI S.L.; DUCHARME N.G. (Eds.). Farm animal surgery. Saint Louis: Saunders, 2004. p.258-262.

THOMAS, D.L.; WALDRON, D.F.; LOWE, G.D. et al. Length of docked tail and the incidence of rectal prolapse in lambs. J. Anim. Sci., v.81, p.2725-2732, 2003.

UENO, H.; GONÇALVES, P.C. Manual para diagnóstico de helmintoses de ruminantes. 4.ed. Tokyo: Japan International Cooperation Agency, 1998. 143p.

ZANOLINI, B.; OBERBAUER, A.M.; PRIEN, S.D. et al. Effect of sex, breed, callipyge phenotype, and docked tail length on rectal prolapse in lambs. Sheep Goat Res. J., v.29, p.510, 2014. 